\section{Induction Current from Leyden-jar Discharge}

I was led to try the following simple experiments with the current induced from Leyden jar discharge, from the knowledge of what is the case in the Ruhmkorf's coil induced currents.

I have since found the experiments have often been tried before; but all may not be aware how simply and easily the results are shown.

After trying flat coils I found it more convenient to coil stout insulated wire round glass tubes. A few yards of stout wire round a tube $\mathrm{A}$ one foot long and $\mathrm{I}_{4}^{\mathrm{T}}$ inches diameter gave me my primary coil ; a similar tube $B$ of less diameter to put inside $\mathrm{A}$ formed my secondary; and a third coil $\mathrm{C}$ enabled me to examine the current induced in $\mathrm{B}$, with respect to its magnetising power, at a distance, away from the influence of the primary $A$. An electrical machine, a Leyden jar or two, a number of un magnetised knitting-needles marked with paper at one end, and a compass-needle to test polarity, are also required.

The experiments are as follows :-

(I) With coil A alone show that a needle is magnetised according to Ampere's law ; if we regard the direction of current to be from the + coat of the jar to the - coat.

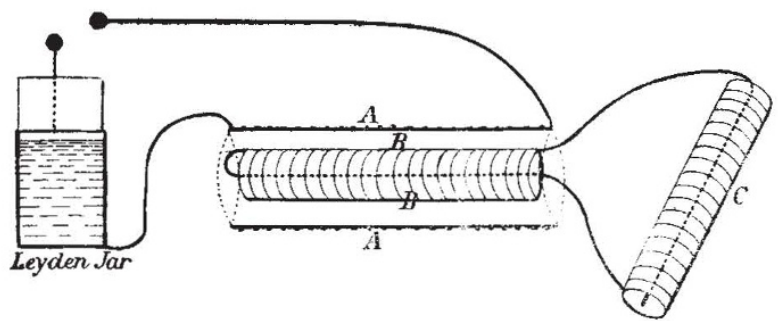

(2) Now arrange the coils as shown, A as primary, B as secondary, $\mathrm{C}$ in the circuit of $\mathrm{B}$, and a needle in $\mathrm{C}$. Let there be no break in the circuit of $\mathrm{B}$ and $\mathrm{C}$.

Then the magnetism induced in knitting-needle shows by (1) an action as of a current inverse to that in A.

(3) Now interpose a break in circuit of B and C, so that induced current gives a spark. We now get the needle oppositely magnetised, showing a direct induced current ; and the magnetisation is far stronger than in (2).

This points to the two opposite induced currents both passing when there is no air-break ; and the inverse having the strongest magnetising action; but the result weak. An air-break stops the inverse current, and the far greater effect of the direct current un-neutralised by the inverse is very marked; it can easily be shown to a class, for example.

I may add that I have been unable to try what results one gets with galvanometers from lack of instruments.

Cheltenham

W. LARDEN

\section{Classification of the Indo-Chinese and Oceanic Races}

IT is surprising that Mr. Murton should have had any difficulty about the characters used by me to indicate the word Papiizwah. The form in question is identical with his own, the apparent difference being due to the two different characters respectively employed by us to express the labial $p$. In the Arabic alphabet there is no sign for this letter, because the sound does not occur in the Arabic phonetic system. Hence other Muhammadan nations using the Arabic alphabet supply the missing letter in various ways, the Persians, Afghans, and Indians by the form , the Malays usually by $\ddot{\xi}$. Hence the two apparently

different but really identical forms which have puzzled Mr. Murton and his Malays of Singapore.

A. H. KEANE.

\section{Crabs and Actinia}

THE account of the actinia on the claws of a crab in your last number (p. 515) is of interest as raising the point as to what benefit the crab cerives from its friends. In the Annals of Natural History, many years ago, I wrote that, having for a long period kept Adamsia palliata with $P$. Prideauxii in confinement, I had no doubt but that the white tentacles of the anemone were a bait which attracted various snall animals within reach of the crab's claws, though it did not, as Möbius seems to think, in any way aid the crab in capturing its prey.

In the South Sea Islands $I$ saw a splendid specimen of a crab carrying a large actinia. The habit of the crab was to conceal itself entirely in the sand, leaving the actinia waving its tentacles on the surface. No sooner however did a small crab, annelid, or other creature come within reach than the crab, shooting its elaw out of its concealment in the sand, struck out, and in most cases captured it. Here there was no doubt of the use of the
actinia as a decoy.
H. STUART WORTLEY

Patent Office Museum, South Kensington, W., April 4

\section{Migration of the Wagtail}

WiTH reference to the statement of Herr Adolf Ebeling (apud the correspondence from the New York Evening Post, quoted in your issue of February 24, vol. xxiii. p. 387 ), that the fact that wagtails in their wintering "came to Africa, and especially to Nubia and Abysssinia, was then unknown to us," permit the remark that as "then" must refer to a date not earlier than I850 (when Heuglin went to Egypt), the appearance of wagtails on the west coast of Africa, as far south as Cape Verd, had been observed more than balf a century before.

In the Annales de Chimie for July, 1793, M. Prélong, one of the lieutenants of Stanislas, Chevalier de Boufflers, and director of the hospital at Gorée, records the arrival on September I4, I 788, of a flight of bergeronnettes from the north. In connection with this M. Prélong rememkered that Adanson had seen swallows at Senegal October 9, I750 (?), while he himself could testify to their leaving his native pays (the Hautes-Alpes) towards the end of September. Prélong took ship for home in the middle of May, 1789 , and was accompanied by his feathered friends the wagtails.

New York, March 15

N. I.

\section{Sound of the Aurora}

UPON this subject it may not be out of place to recall the fact that the passage of large meteors is not uncommonly described as accompanied by a hissing sound. I have met with statements of this kind in the case of meteors which were proved to have been twenty, thirty, or forty miles distant from the observer, and the sound of which, therefore, if it had reached him at all, must have reached him after such an interval of time that he would have been very unlikely to connect the two phenomena. Moreover the sound described in these cases is of a totally different character from the true sound of meteors, which is spoken of by those who have heard it as a heavy roaring or rumbling sound.

The explanation of the alleged "hissing" is not difficult when we remember that the untrained observer of a bright meteor (although it may be distant fifty or a hundred miles from him) invariably regards it as a near object, falling, it may be, into the next field, or behind a neighbouring hill. Regarding it in this light, he attributes to it, by a well-known mental process, a sound such as a firework at the same distance might be expected to produce.

May not the "rustling" of the aurora be equally a subjective phenomenon? GEORGE F. BURDER

\section{Earthquake Warnings}

Is Comptes rendus, lxxxi. October, 1875 , I find it stated, on the authority of M. Rivet, Telegraph Superintendent at Fort de France, Martinique, that when that island was visited by repeated earthquake shocks in September, 1875 , each shock was preceded by a very marked disturbance of the electric telegraph needles. M. Rivet suggested that in this way warnings otherwise unattainable of impending shocks might be obtained.

It would be interesting to learn whether this observation has been confirmed by recent experience on the Continent.

Such warnings might often be the means of averting loss of life and property, and in cases like that at Ischia would, by their occurrence or non-occurrence, afford some additional clue to the real nature of the forces at work.

H. M. C.

Charlton, March $3 \mathbf{r}$ 